\title{
NOTKERS
}

\section{DES DEUTSCHEN WERKE}

NACH DEN HANDSCHRIFTEN

NEU HERAUSGEGEBEN

VON

E. H. SEHRT UND TAYLOR STARCK

DRITTER BAND - DRITTER teIL

DER pSaLter - PSALMUS CI-CL

NEBST CANTICA UND KATECHETISCHEN STUCKEN

HERAUSGEGEBEN

VON

EDWARD H. SEHRT

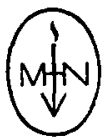

VEB MAX NIEMEYER VERLAG - HALLE/SAALE 
Alle Rechte,
auch das der UUbersetzung in fremde Sprachen, vorbehalten

Altdeutsche Textbibliothek, begründet von H.Paul $†$ fortgeführt von G. Baesecke $\dagger$

Nr. 43 